\title{
A pecuária leiteira e o desenvolvimento da Região Noroeste do Rio Grande do Sul
}

\author{
Emerson Juliano Lucca \\ Universidade de Santa Cruz do Sul (UNISC) \\ Silvio Cezar Arend \\ Programa de Pós-Graduação em Desenvolvimento Regional / Universidade de Santa Cruz do Sul (UNISC)
}

Recebido: 25/05/2019 Versão revisada (entregue): 28/10/2019 Aprovado: 31/10/2019

\begin{abstract}
Resumo
Este artigo discute as transformações ocorridas na cadeia produtiva do leite, relacionadas à modernização, evidenciando uma aproximação das indústrias processadoras aos produtores de leite. Isto se deve aos efeitos da dinamização das atividades econômicas que, ao demandar modernização das técnicas de manejo, genética, ampliações de instalações, investimentos em tecnologia, gestão e novos instrumentos de trabalho, interligam os agentes pertencentes à cadeia produtiva do leite. Com o objetivo de discutir a relevância produtiva da pecuária leiteira, enfatizou-se a região Noroeste do estado do Rio Grande do Sul. Para isso, fez-se pesquisa bibliográfica sobre a cadeia produtiva do leite, a diversificação produtiva das indústrias processadoras, a estrutura de processamento das indústrias e o volume de produção dos produtores de leite. Constatou-se que a nova dinâmica do setor tem motivado os agentes integrantes da atividade leiteira à adoção de novas técnicas, incluindo manejo, profissionalização e cuidados na gestão das propriedades, favorecendo avanços nos processos de produção e comercialização como estratégia de permanência na atividade.
\end{abstract}

Palavras-chave | Cadeia produtiva do leite; diversificação; indústrias processadoras; modernização; produtores de leite; Rio Grande do Sul.

Código JEL | O13 Q13 R11

\section{Dairy farming and the development of the Northwest Region in Rio Grande do Sul}

\begin{abstract}
This article discusses the transformations that occurred in the milk production chain, related to the modernization, evidencing an approximation of the processing industries to the milk producers. This is due to the effects of the dynamization on economic activities, which, by demanding modernization of management techniques, genetics, expansion of facilities, investments in technology, management and new instruments of work, interconnect agents belonging to the milk production chain. In order to discuss the productive relevance of dairy farming, the Northwest region of the state of Rio Grande do Sul (RS) was emphasized. To this
\end{abstract}


end, bibliographical materials were used, corresponding to the definitions of the productive chain of milk, the productive diversification of the processing industries, the processing structure of the industries and the volume of production of the milk producers. Thus, the new dynamics of the sector has motivated the agents involved in the dairy activity in the propagation of new techniques, management, professionalization and care in the management of the properties, providing advances in the production and commercialization processes, as a strategy of permanence in the activity.

Keywords | Diversification; milk producers; milk production chain; modernization; processing industries; Rio Grande do Sul.

JEL-Code | O13 Q13 R11

\section{La pecuaria lechera y el desarrollo de la Región Noroeste de Rio Grande do Sul}

\section{Resumen}

El presente artículo discute las transformaciones ocurridas en la cadena productiva de la leche, relacionadas a la modernización, evidenciando una aproximación de las industrias procesadoras a los productores de leche. Esto se debe a los efectos de la dinamización de las actividades económicas que, al demandar modernización de las técnicas de manejo, genética, ampliaciones de instalaciones, inversiones en tecnología, gestión y nuevos instrumentos de trabajo, interconectan a los agentes pertenecientes a la cadena productiva de la leche. Con el objetivo de discutir la relevancia productiva de la pecuaria lechera, se enfatizó la región Noroeste del estado de Rio Grande do Sul (RS). Para ello, se realizó una investigación bibliográfica sobre la cadena productiva de la leche, la diversificación productiva de las industrias procesadoras, la estructura de procesamiento de las industrias y volumen de producción de los productores de leche. Se constató que la nueva dinámica del sector ha motivado a los agentes integrantes de la actividad lechera a la adopción de nuevas técnicas, incluyendo manejos, profesionalización y cuidados en la gestión de las propiedades, proporcionando avances en los procesos de producción y comercialización, como estrategia de permanencia en la actividad.

Palabras clave | Cadena productiva de la leche; diversificación; industrias procesadoras; modernización; productores de leche; Rio Grande do Sul.

Codigo JEL | O13 Q13 R11

\section{Introdução}

A pecuária leiteira é uma das atividades mais importantes do setor agropecuário e desempenha função de vital relevância no processo de desenvolvimento econômico e social do país. Entretanto, em seu processo histórico, e de maneira mais significativa nas últimas décadas, o cenário da atividade leiteira experimentou 
diversas modificações em toda extensão da sua cadeia produtiva, havendo uma reestruturação social, política e econômica dos diversos setores da atividade.

As transformações ocorridas nas atividades derivadas da cadeia produtiva do leite se devem a sua dinâmica econômica global, que apresenta um novo modelo mercadológico. Esse, segundo Ploeg (2008), relaciona-se com as atuais formas de globalização. Emerge, assim, um novo enfoque ao conceito de desenvolvimento rural, baseado na definição multidimensional do desenvolvimento, envolvendo a dimensão econômica, sociocultural, político institucional e ambiental (CONTERATO, 2008; KAGEYAMA, 2004; PLOEG et al., 2000).

O desenvolvimento rural brasileiro recebe influência de diversas conjunturas e, principalmente, dos novos condicionantes que o desenvolvimento da economia e da vida social gradualmente impõem às famílias e às atividades rurais. As propriedades produtoras de leite são, em grande parte, possuidoras de um intenso dinamismo produtivo e econômico e estão vivenciando um processo de modernização.

A modernização aqui discutida tem como conceito o uso intensivo de equipamentos e técnicas, tais como máquinas e insumos modernos, que permite maior rendimento no processo produtivo. Assim, modernização da agricultura assumiu como sinônimo de mecanização e tecnificação. A modernização impulsiona a "industrialização da agricultura", tornando-a uma atividade nitidamente empresarial, abrindo um mercado de consumo para as indústrias de máquinas e insumos modernos; elevação da produtividade do trabalho visando o aumento do lucro; redução dos custos unitários de produção para vencer a concorrência e melhores condições de enfrentar as dificuldades impostas pela natureza no que concerne à produção (BRUM, 1988; TEIXEIRA, 2005).

De acordo com Navarro (2001, p.88), estas teorias preconizavam "[...] a intensificação tecnológica e a crescente absorção de insumos modernos pelos produtores, como parte de uma estratégia de aumento da produtividade e, como objetivo final, a elevação da renda dos produtores". Ploeg et al. (2000) enfatizam a intensificação no uso de insumos, produção orientada pela lógica de mercado, especialização e inovações tecnológicas. Estas contribuições são as primeiras noções de desenvolvimento rural, que segundo Navarro (2001), estão ligadas ao conceito de crescimento econômico, pois buscavam o aumento da produtividade e da renda.

O referencial teórico busca explicar que a pecuária leiteira vem conquistando grande importância na economia brasileira e começou a ser desenvolvida com maior intensidade nas últimas décadas. Desde o início do processo de colonização do território brasileiro a atividade vem desempenhando papel importante na estrutura produtiva, com forte influência na expansão econômica, destacando-se na pauta das exportações e, também, no abastecimento do mercado interno, 
importante para gerar renda para produtores de leite e demais integrantes da cadeia produtiva.

As mudanças ocorridas na cadeia produtiva do leite a partir das últimas décadas têm acirrado a concorrência no setor, obrigando as indústrias a investir cada vez mais na qualidade da matéria-prima. Assim a padronização das normas de qualidade do leite impôs uma série de exigências para o mercado de lácteos, determinando maior compromisso social, econômico e político de todos os elos envolvidos na cadeia (GIGANTE, 2004; MONARDES, 2004).

Estas transformações fizeram com que as famílias do meio rural mudassem suas relações comerciais e sociais, assumindo um papel importante na integração de produtores de leite com o mercado, fragilizando a unidade de produção pela dependência do mercado, mas também oportunizando um conjunto de novas atividades. Desta forma, levanta-se a seguinte questão de pesquisa: a diversificação produtiva das indústrias processadoras, estrutura de processamento e volume de produção, são considerados instrumentos necessários para que atividade continue se desenvolvendo e gerando trabalho para todos os agentes da cadeia produtiva?

Com o objetivo de discutir a relevância socioeconômica da pecuária leiteira, o presente artigo aborda, inicialmente, a caracterização da cadeia produtiva do leite no Rio Grande do Sul (RS). Na sequência, faz-se uma reflexão sobre os avanços e perspectivas da cadeia produtiva do leite nacional, com enfoque na Região Noroeste do RS, apresentando a diversificação produtiva das indústrias processadoras, para, posteriormente, enfatizar a estrutura de processamento e produção de leite estadual.

Metodologicamente, o estudo baseou-se na taxionomia proposta por Gil (2008), que classifica a pesquisa quanto aos fins e aos meios. Quanto aos fins, trata-se de uma pesquisa descritiva, abordando aspectos da caracterização da cadeia produtiva do leite, avanços e perspectivas, diversificação das indústrias processadoras, estrutura e volume de produção das propriedades da região Noroeste do RS. Quanto aos meios, trata-se de uma pesquisa bibliográfica, pois baseou-se em material publicado disponibilizado em livros, artigos e informações do meio eletrônico. O tratamento se deu por meio da análise de conteúdo reflexiva, buscando responder à questão proposta.

\section{Caracterização da cadeia produtiva leiteira}

As transformações que ocorreram no espaço agrário e, em especial, na cadeia produtiva do leite do RS após a década de 1950 foram responsáveis pelas significativas mudanças nos territórios do estado. A estrutura fundiária presente se diferencia de acordo com a região, alternando predomínio de grandes e médias unidades de produção com médias e pequenas (PORTO et al., 2010). 
O estado é, tradicionalmente, um grande produtor de leite e essa atividade, que começou com características extrativistas, já ocupa posição de destaque no cenário econômico nacional. No entanto, para atingir esse patamar de destaque, a cadeia produtiva do leite, o setor lácteo e seu encadeamento produtivo passaram por mudanças expressivas ao longo das últimas décadas (VIANA; FERRAS, 2007).

Os avanços no processo de industrialização, o incremento na utilização de tecnologias e as mudanças nas instruções normativas resultaram em movimentos de reestruturação em todos os elos da cadeia. Essas transformações apresentam uma heterogeneidade no processo produtivo, colocando o agricultor como o elo mais frágil na cadeia, necessitando aprimorar-se constantemente (CASTRO et al., 1998).

No entendimento de Carvalho e Fortes de Oliveira (2006), a presença familiar é característica marcante na cadeia leiteira. Esse envolvimento permite que produtores inseridos na atividade explorem suas áreas para obter renda e trabalho em suas propriedades, tornando-se uma forma interessante de ocupação, transformação e de incentivo à autonomia familiar no quesito socioeconômico.

A sequência de fatores que revolucionaram os setores produtivos do leite, trouxeram reflexos diretos entre os elos atuantes da cadeia. Esses reflexos proporcionaram aumento significativo da produtividade, redução do número total de produtores, concentração da produção, fusões da indústria processadora e aumento da concorrência no mercado interno (GOMES, 2001).

As modificações na cadeia do leite vêm surpreendendo a atividade, caracterizando como um sistema composto por vários setores econômicos que, entre si, estabelecem diferentes relações, articulados em um processo produtivo. Brum (2012) acrescenta que a cadeia produtiva é considerada como uma sucessão de operações e transformações, que interligadas a um conjunto de relações comerciais e financeiras estabelecem um fluxo de troca entre fornecedores e clientes, situado à montante e à jusante (HANSEN, 2004).

A organização da cadeia produtiva do leite, de acordo com Zylbersztain (2000); Canziani (2003); Brum (2012); Duarte (2017), está conectada entre os elos da sua estrutura e compartilha ações entre grandes áreas da produção. O primeiro elo é a "produção" que relaciona fornecedores, fabricantes de insumos (sementes, adubos, rações máquinas e implementos), bem como todos os serviços de apoio necessários (gestão, qualificação, assistência técnica, mão de obra, crédito) e todos os fatores de produção disponíveis. No segundo, encontra-se a "propriedade rural", o produtor de leite que fará uso dos insumos para gerar novos subsídios. O terceiro, "logística" processo ou serviço de captação e distribuição do leite da propriedade para a indústria e, depois, para o mercado. O quarto, a "indústria de transformação" da produção (agroindústria ou cooperativa com planta agroindustrial), que modifica o produto bruto em condições de ser usado pelo consumidor e cuida do marketing do produto. Por último, o quinto elo: o 
"mercado e consumidores", que envolve ainda o atacado e o varejo, além de diversos serviços de apoio que são necessários para propiciar a comercialização ao consumidor final.

Na Figura 1 é possível identificar que a cadeia produtiva do leite é um conjunto de atividades socioeconômicas que se articulam progressivamente desde o início da produção até o consumidor final. Segundo Batalha (2007), é um sistema formado por um conjunto de setores econômicos que estabelecem entre si significativas relações de troca, compra e venda.

\section{Figura 1 - Representação da cadeia produtiva do leite}

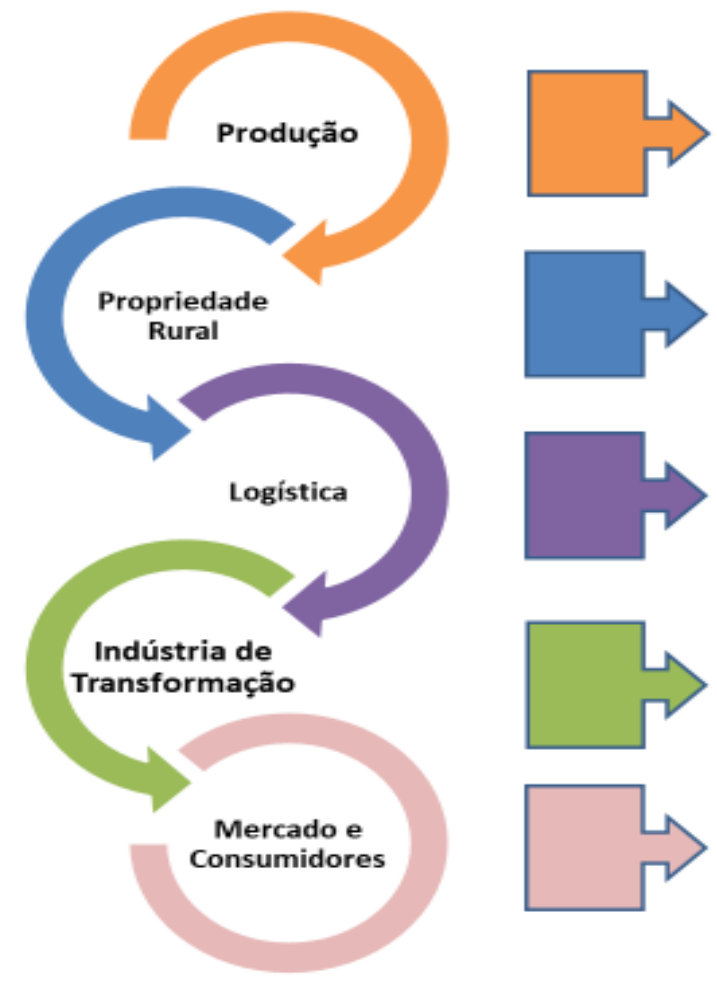

- Fornecedores de insumos, máquinas, implementos

- Produtos Veterinários;

- Alimentação (nutrição dos animais; ração reprodução);

- Equipamentos de ordenha e refrigeração;

- Prestação de serviços assistência (técnica, gestão, crédito, mão de obra, qualificação, pesquisa).

- Todos os produtores rurais:

- Produtores Familiares (Tradicionais)

- Produtores empresariais (em transiçāo)

- Prodatores Capitalistas (modernos, empreeadedores)

- Processo ou serviço de captação e distribuição do leite: da propriedade para a indústria e da indústria para o mercado.

- Indústrias e cooperativas que fazem a industrialização do leite.

- Atacadistas, varejistas e consumidores finais.

Fonte: Adaptado pelos autores com base em Brum (2012); Duarte (2017); Canziani (2003) e Zylbersztain (2000).

A cadeia produtiva do leite representada exibe interação entre os elos, sendo que, em determinados ocasiões, um ou outro possui certa autoridade sobre os demais, o que ocorre pela sua força e pelo seu poder de mercado (VIANA; FERRAS, 2007). Portanto, todos os elos da cadeia produtiva do leite, cumprem um papel fundamental no desenvolvimento de cada setor, sendo que o mais forte é considerado o da indústria de transformação, que detém o poder de modificar a matéria-prima e agregar valor ao produto, ganhando na compra dos insumos e na venda do produto final. 
As grandes áreas da estrutura da cadeia produtiva do leite estão representadas pelos principais elos provenientes da formação, estruturação, dos agentes que interagem na produção, comercialização dos insumos e produtos ligados à pecuária leiteira. Para Canziani (2003), os elos envolvem uma corrente de segmentos que permite uma visão ampliada de cada área, compreendendo a dinâmica existente na cadeia do leite: indústria de implementos agrícolas, fornecedores de máquinas e insumos, mão de obra dos produtores de leite, colaboradores, transportadores do leite da propriedade até a fábrica e da indústria até o mercado, processamento da matéria-prima, incluindo a distribuição do produto final ao consumidor.

Os circuitos de momentos produtivos dos vários setores e subsetores da cadeia do leite começam na composição dos insumos, processamento, transformação, comercialização e distribuição dos equipamentos necessários à exploração da atividade leiteira (VIANA; FERRAS, 2007). A confecção de máquinas para ordenha, ração, medicamentos, fertilizantes, sementes, inseminação são considerados instrumentos necessários para que atividade continue se desenvolvendo e gerando trabalho para todos os agentes da cadeia produtiva. Esses instrumentos impulsionam a atividade levando ao produtor tecnologia, conhecimento e inovação.

O fluxo que interliga os elos da cadeia do leite é de suma importância para a viabilidade das atividades desenvolvidas pelos produtores de leite, fornecedores, transportadores, indústrias processadoras e mercado (CANZIANI, 2002). Essa corrente visa os gargalos da atividade, a garantia de mercado e a comercialização da sua produção em todos os segmentos da cadeia. Portanto, a cadeia do leite constitui um conjunto de etapas consecutivas pelas quais perpassam processos de transformação, reorganização, modificações na produção, industrialização, comercialização de leite e derivados e demais insumos (PROCHNIK; HAGUENAUER, 2002).

\section{Avanços e perspectivas na cadeia produtiva do leite no RS}

Partindo do cenário nacional, o Brasil encontra-se em quarto lugar na produção mundial de leite, de acordo com a Food and Agriculture Organization (FAO) (EMBRAPA GADO DE LEITE, 2018), com aproximadamente 35 bilhões de litros/ano (MARTINS et al., 2018). Essa posição já vem sendo ocupada há cerca de três anos, segundo levantamentos realizados pela Empresa Brasileira de Pesquisa Agropecuária (EMBRAPA), e indica que a atividade leiteira vem evoluindo de forma contínua, resultando em um crescimento consistente na produtividade. 
Esse constante crescimento que o Brasil vem apresentando reflete diretamente nas escalas de produção, dispersas por todo o território nacional, caracterizada pela grande heterogeneidade que existe entre o tamanho das propriedades, tipos de produtores, rebanho e tecnologias de produção adotadas (CARVALHO et al., 2007). Nos últimos anos, o incremento acentuado na produção fez com que os produtores se especializassem na atividade, tendo como perspectivas a médio ou longo prazo, tornar-se um importante exportador de leite e de produtos lácteos.

O RS é o quinto maior estado do Brasil, com extensão territorial de 281.748,5 $\mathrm{km}^{2}$, ocupando cerca de 3\% do território brasileiro. Conforme a Fundação de Economia e Estatística - FEE (2017), o estado possui aproximadamente 11,3 milhões de habitantes, divididos entre 497 municípios. A área total dos estabelecimentos agropecuários identificados pelo Censo de 2017 é de aproximadamente 21.680.991 hectares, sendo $6,7 \%$ a mais que no último levantamento, em 2006 (IBGE, 2017). A estimativa do Censo Agropecuário 2017 sinalizou que 365.052 mil estabelecimentos agropecuários foram cadastrados, ou seja, teve uma variação negativa de $17,3 \%$ em relação ao Censo realizado em 2006, quando foram registrados 441.472 mil estabelecimentos (FEE, 2017).

A cadeia produtiva do leite nas regiões produtoras do RS vem se evidenciando devido ao grande montante de recursos que estão sendo investidos em propriedades rurais, ampliação da capacidade de armazenamento das indústrias processadoras e pela saída dos produtores da atividade. Esses três fatores demostram a diversidade de ações que estão acontecendo na cadeia produtiva no que se refere aos investimentos realizados em propriedades produtoras de leite, ampliações do armazenamento nas indústrias processadoras e a questão social que transcorre pela saída dos produtores da atividade leiteira.

O aumento do volume de produção de leite nos últimos anos no RS despertou o interesse da indústria processadora e das que produzem os insumos que são utilizados para o cultivo, manejo e produção do leite. Esse conjunto de produtos, utilizados no dia a, permite que produtores com potencial de conhecimento usufruam das ferramentas disponíveis e as transformem em recursos para a propriedade.

As condições favoráveis de clima, solo, topografia genética e estrutura fundiária configuram um quadro positivo para as principais regiões produtoras. As regiões do estado que apresentam estas características demonstram competitividade e potencial para tornar a atividade uma fonte de renda para os produtores que possuem menores áreas produtivas. Em decorrência disso, a produção de leite tornou-se atividade para a composição de renda de um número expressivo de produtores que salientam o crescimento da produção em escala e produtividade (BASSO; SILVA NETO, 1999). 
Corresponde, aproximadamente, a $7 \%$ do Produto Interno Bruto (PIB) do agronegócio, além de gerar desenvolvimento para as famílias produtoras de leite, proporciona um conjunto de atividades na indústria de laticínios, que gera empregos para pessoas da área urbano (FAUTH; FEIX, 2015). Esse comportamento é importante para o desenvolvimento econômico estadual, já que possui um encadeamento forte com a área urbano (MONTOYA; FINAMORE, 2010).

Nas últimas décadas, a produção leiteira do RS aumentou em todas as regiões, valendo-se de ganhos em relação à produtividade. Esse movimento ocorre em propriedades que estão buscando inovação, melhoramento genético e realizando o manejo de forma adequada.

A Região Noroeste do estado do RS, especializada na produção de leite (SILVA NETO; BASSO, 2005), vem buscando aumentar sua especificação, proporcionando aos envolvidos uma expansão na economia das atividades ligadas à cadeia produtiva e, ao mesmo tempo, gerar efeitos multiplicadores em atividades subsidiárias e complementares da economia regional (TRENNEPOHL, 2010).

Com estas constatações, os investimentos por parte das indústrias de laticínios, bem como incentivos governamentais, são cada vez mais evidentes na região. Trazem consigo novas técnicas de trabalho, modernização da atividade, gestão nos processos, assim como ferramentas que reduzem a penosidade na atividade (JANTSCH et al., 2011). Essas técnicas permitem que produtores desenvolvam características de multifuncionalidade, diversificando as funções na atividade leiteira e conciliando o tempo de trabalho com outros sistemas de produção.

Dessa forma, a produção de leite vem comprovando boas perspectivas para o Brasil, em especial para a Região Noroeste do estado do RS. É através deste produto que a atividade leiteira participa na formação da renda de grande número de produtores, além de ser responsável por elevada absorção de mão de obra rural (contratada e familiar), propiciando a fixação do homem no campo. Por conseguinte, a atividade ainda enfrenta dificuldades em relação aos custos de produção, baixo poder aquisitivo dos produtores e pela reduzida produtividade do rebanho, principalmente nas pequenas propriedades.

Assim, a cadeia produtiva do leite, que busca consolidação, passa por profundas transformações e procura aprimorar sua organização e crescimento econômico para dar sustentabilidade aos agentes envolvidos na atividade. Segundo pesquisas realizadas por Martins (2005), a atividade leiteira vem ganhando espaço na cadeia produtiva e busca sua reestruturação no mercado. Essa batalha exige que produtores e indústrias busquem especialização, tecnologias e muitas estratégias para continuarem firmes na atividade. A inserção de novas tecnologias pode contribuir para aumentar a eficiência nos afazeres, tanto da indústria quanto dos produtores, proporcionar uma visão da gestão da propriedade e beneficiar os trabalhadores nas penosidades da atividade. 


\section{Diversificação produtiva das indústrias processadoras do RS}

Em se tratando de diversificação produtiva, observa-se que as indústrias ligadas ao setor lácteo gaúcho possuem um número elevado de empresas produtoras que desenvolvem algum tipo de atividade relacionada à cadeia produtiva do leite. Portanto, a intensificação das indústrias processadoras presentes no estado é caracterizada pela dinamização econômica embasada fortemente pela urbanização, pela industrialização e pela modernização das técnicas de cultivo no campo (FONTOURA, 2014).

Deste modo, a concentração de produtores e de indústrias processadoras no Noroeste gaúcho é uma tendência que vem se consolidando, em especial na última década, aliando o sistema de produção agrícola já consolidado (sojicultura) com a de leite. Este deslocamento da produção leiteira só foi possível devido à introdução do leite UHT (Ultra High Temperature), que permitiu que as unidades produtoras se instalassem longe dos principais centros consumidores, possibilitando ao setor lácteo ocupar o mercado mundial (TRENNEPOHL, 2011).

A utilização desta nova tecnologia de ultrapasteurização (processo UHT), amplia o prazo de validade do produto, sem necessidade de refrigeração e sem significativas alterações nas características essenciais do leite ou de sabor. Este procedimento permitiu que o leite fosse distribuído em distâncias crescentes dos centros de produção, mudando de forma definitiva o mapa de produção no país. Deste modo, foi registrado uma mudança extraordinária no processo de distribuição, embalagem, manutenção da qualidade e prazo de validade que deram uma maior garantia ao consumidor. O processo de concentração na indústria de laticínios brasileira foi intenso, com algumas empresas se destacando devido às estratégias agressivas de ação, tanto na compra da matéria-prima como na disputa pelos mercados finais (JANK; GALAN, 1999). Essa aglomeração pode ser observada no estado do RS, que demonstra ao longo das décadas um expressivo movimento por parte das indústrias processadoras em se instalarem, bem como ampliarem suas plantas industriais, em especial, na Região Noroeste. A concentração pode resultar da expansão da empresa pelo aumento do investimento na unidade produtiva ou pode ocorrer pela fusão, aquisição ou formação de joint venture.

Esses processos de integração e alianças já ocorriam entre os laticínios na década de 1980. Nesse período, mais da metade das empresas passaram por algum procedimento de aquisição ou desenvolvimento de aliança estratégica. Com o passar dos anos, esse movimento foi se intensificando e, na década de 1990, quando as modificações já estavam em curso, foi possível perceber alterações no ranking das maiores empresas captadoras de leite (JANK et al., 1999; CARVALHO, 2000). 
Desde a virada dos anos 1990, este setor produtivo passou por ajustes que, segundo Jank e Galan (1999), resultaram em um ambiente competitivo completamente novo. Esse ambiente exige das indústrias de beneficiamento e de insumos, bem como dos produtores rurais, um enorme envolvimento e compromisso para que os setores da economia continuem proporcionando impactos positivos na cadeia produtiva do leite (MONTOYA; FINAMORE, 2005). A qualificação profissional de produtores e técnicos que estão envolvidos diretamente na atividade pode contribuir positivamente para o melhor entendimento do processo de desenvolvimento regional.

O número de indústrias processadoras e unidades de resfriamento no RS vem se consolidando nos últimos anos devido ao forte processo de fusões e aquisições que se fizeram presentes no estado. A distribuição de empresas por regiões dá uma noção de como a atividade tem relevância para as indústrias processadoras. A região há maior concentração de delas fica no Norte do estado, território em que se constatou maior concorrência entre empresas para a aquisição de leite dos agricultores, investimentos e grande quantidade de plantas industriais instaladas.

No Quadro 1 é possível visualizar indústrias processadoras de leite que se encontram na Região Noroeste e/ou próxima a ela. Entre as indústrias apresentadas, é possível identificar que algumas das maiores empresas processadoras da matéria-prima do Brasil possuem suas plantas industriais no RS. 
Quadro 1 - Plantas industriais captadoras de leite e unidades de resfriamento na Região Noroeste e RS

\begin{tabular}{|c|c|c|}
\hline Nome da indústria processadora & Cidades & Logomarca da indústria \\
\hline NESTLÉ - Nestlé S.A. & $\begin{array}{l}\text { Palmeiras das Missões; } \\
\text { Carazinho }\end{array}$ & \\
\hline $\begin{array}{l}\text { CCGL - Cooperativa Central } \\
\text { Gaúcha Ltda. }\end{array}$ & Cruz Alta & Leite de verdade \\
\hline $\begin{array}{l}\text { PIRANCAJUBA - Laticínios } \\
\text { Bela Vista }\end{array}$ & Nova Ramada & \\
\hline $\begin{array}{l}\text { ITALAC - Goiasminas Indústria } \\
\text { de Laticínios Ltda. }\end{array}$ & $\begin{array}{l}\text { Giruá; Tapejara; Passo } \\
\text { Fundo }\end{array}$ & \\
\hline LACTALIS - Grupo Lactalis & $\begin{array}{c}\text { Ijuí; Santa Rosa; Três } \\
\text { de Maio }\end{array}$ & \\
\hline $\begin{array}{l}\text { LATVIDA - Indústria de } \\
\text { Alimentos Estrela S.A. }\end{array}$ & $\begin{array}{c}\text { Estrela; Coronel } \\
\text { Barros* } \\
\end{array}$ & \\
\hline $\begin{array}{l}\text { COOPERMIL - Cooperativa } \\
\text { Mista São Luiz }\end{array}$ & Santa Rosa & \\
\hline $\begin{array}{l}\text { EMBARÉ S.A - Embaré } \\
\text { Indústrias Alimentícias S.A. }\end{array}$ & Sarandi & \\
\hline $\begin{array}{l}\text { SANTA CLARA - Cooperativa } \\
\text { Santa Clara }\end{array}$ & Carlos Barbosa & Santåclara \\
\hline $\begin{array}{l}\text { LANGUIRU - Cooperativa } \\
\text { Languiru }\end{array}$ & Teutônia & LANGUIRU \\
\hline $\begin{array}{l}\text { DALIA/COSUEL - } \\
\text { Cooperativa dos Suinocultores } \\
\text { de Encantado Ltda. }\end{array}$ & $\begin{array}{c}\text { Encantado; Arroio do } \\
\text { Meio }\end{array}$ & \\
\hline TIROL - Laticínios Tirol S.A. & Tiradentes do Sul & \\
\hline PIÁ - Cooperativa PIÁ & Nova Petrópolis & \\
\hline
\end{tabular}

* Planta industrial em fase de elaboração.

Fonte: Adaptado pelos autores com base nos sites das empresas processadoras de leite 2018.

Dentre as indústrias processadoras citadas, as que estão mais próximas dos produtores de leite da Região Noroeste, são: CCGL; Lactalis; Nestlé, Piracanjuba; Italac; Coopermil; Lactivida e Santa Clara. Essas são as principais indústrias captadoras da região que constroem uma relação de proximidade com os 
produtores de leite devido à concentração de plantas industriais localizadas perto da região em estudo.

Por conseguinte, foi possível observar que muitos munícipios não possuem empresas processadoras em suas sedes, o que é compreensível, já que as cadeias produtivas de leite se estruturam regionalmente. Segundo Breitenbach e Souza (2015), esse movimento ocorre no estado, pois ele compõe em seu limite territorial municípios próximos, não havendo necessidade de instalações de plantas industriais de grandes infraestruturas devido ao pequeno número de habitantes e a proximidade entre eles.

É nítido o predomínio de grandes grupos empresariais, nacionais e multinacionais, diversificados e especializados neste território. Estes grupos destacam-se no mercado, com lançamentos e novidades que ganham a preferência do consumidor, em um mercado com tendência de demanda crescente (VIEIRA FILHO; FISHLO, 2017).

As indústrias, ao beneficiarem a matéria-prima, tanto leite quanto ração, conseguem gerar uma maior eficiência nos processos, tornando-as mais completas e atraentes para os produtores de leite. Essas indústrias, ao utilizarem tecnologias de última geração, conseguem produzir uma diversidade de produtos, atendendo os diferentes estilos de produtores. Devido a essas técnicas inovativas (máquinas, embalagens, transporte e logística aplicativos gerenciais) os processos de produção, vendas e distribuição totalmente automatizados são considerados os meios mais eficazes de aumentar a produtividade, atingir a qualidade exigida pela competição do mercado e, assim, o lucro desejado e satisfação do produtor.

Deste modo, o desempenho dessas indústrias tem sido avaliado pela sua capacidade de produção, qualidade dos insumos utilizados, diversificação (produtos e serviços), competitividade e a forma de distribuição empregada. Essas variáveis completam as relações, operações e especificidades da indústria, bem como o aumento da sua capacidade produtiva.

$\mathrm{Na}$ Região Noroeste do estado, o número de empresas que fornecem a matériaprima para os produtores de leite vem crescendo nos últimos anos. No Quadro 2 é possível identificar as indústrias que estão se especializando na produção de ração para bovinos de leite.

A produção de leite é uma atividade complexa cujo sucesso depende da integração dos componentes do sistema produtivo. O desempenho de rebanhos leiteiros está intimamente associado com o manejo nutricional que é. Segundo Tomich et al. (2015), as empresas que se especializam na atividade estão buscando diversificar suas estratégias para aumentar a eficiência em relação ao uso de insumos, incrementando a produtividade, contribuindo para a obtenção de um baixo custo e atendendo todas as necessidades da propriedade produtora. Tais técnicas estão atreladas aos equipamentos utilizados na propriedade (ordenha mecanizada; carrossel; desensiladeira; sistemas free stall, semi-confinado e compost barn; 
gerenciamento e controle de produção; e assistência técnica) que contribuem para o desenvolvimento e manutenção dos produtores na atividade.

Como consequência do aumento da produção de leite, a competitividade entre as indústrias que trabalham no setor de alimentação animal vem apresentando uma forte concorrência. Esta competição gira em torno da qualidade dos produtos ofertados, preços e formulação da ração apresentada para o produtor. Esses quesitos são considerados essenciais para que o relacionamento entre indústria/produtor seja duradouro (CASTRO et al., 1998). 
Quadro 2 - Empresas fornecedoras de ração de origem animal para bovinos de leite

\begin{tabular}{|c|c|c|}
\hline Nome da indústria processadora de ração & Cidades & $\begin{array}{l}\text { Logomarca da indústria de } \\
\text { ração }\end{array}$ \\
\hline COTRIPAL - Agropecuária Cooperativa & Panambi & cotripal \\
\hline $\begin{array}{l}\text { COTRIBÁ - Cooperativa Agrícola Mista } \\
\text { General Osório }\end{array}$ & Ibirubá & \\
\hline $\begin{array}{l}\text { PURO TRATO - Puro Trato Nutrição } \\
\text { Animal }\end{array}$ & $\begin{array}{l}\text { Santo } \\
\text { Augusto }\end{array}$ & \\
\hline $\begin{array}{l}\text { NUTREPAMPA - Equilíbrio Em } \\
\text { Nutrição Animal - Jost e Ferreira Ltda. }\end{array}$ & Independência & pa \\
\hline $\begin{array}{l}\text { COTRIJAL - Cooperativa Agropecuária e } \\
\text { Industrial }\end{array}$ & $\begin{array}{l}\text { Não-Me- } \\
\text { Toque }\end{array}$ & \\
\hline RAÇÕES SUPRA & $\begin{array}{l}\text { Sapucaia do } \\
\text { Sul }\end{array}$ & \\
\hline $\begin{array}{l}\text { COTRICAMPO - Cooperativa Tritícola } \\
\text { Mista Campo Novo Ltda. }\end{array}$ & Campo Novo & \\
\hline CAMERA - Camera Agroalimentos S.A. & Santo Cristo & \\
\hline $\begin{array}{l}\text { COTRIMAIO - Cooperativa } \\
\text { Agropecuária Alto Uruguai Ltda. }\end{array}$ & Três de Maio & \\
\hline $\begin{array}{l}\text { COTRIFRED - Cooperativa Tritícola de } \\
\text { Frederico Westphalen }\end{array}$ & $\begin{array}{l}\text { Frederico } \\
\text { Westphalen }\end{array}$ & \\
\hline $\begin{array}{l}\text { COOPERMIL - Cooperativa Mista São } \\
\text { Luiz }\end{array}$ & Santa Rosa & \\
\hline PIÁ - Indústria de Rações & $\begin{array}{c}\text { Nova } \\
\text { Petrópolis }\end{array}$ & \\
\hline $\begin{array}{l}\text { DAMBI / CONSULATI - Cooperativa } \\
\text { Sul Rio-Grandense de Laticínios e Rações }\end{array}$ & Pelotas & - बos \\
\hline $\begin{array}{l}\text { AGROPAN - Cooperativa Agrícola } \\
\text { Tupanciretã }\end{array}$ & Tupanciretã & $\frac{7 \times}{99010}$ \\
\hline LANGUIRU - Cooperativa Languiru & Estrela & LANGUIRU \\
\hline $\begin{array}{l}\text { COSUEL/DÁLIA - Cooperativa dos } \\
\text { Suinocultores de Encantado Ltda. }\end{array}$ & Encantado & \\
\hline
\end{tabular}

Fonte: Adaptado pelos autores com base nos sites das empresas produtoras de ração para bovinos de leite 2018. 
Dentre as indústrias citadas acima, as que interagem mais com os produtores da Região Noroeste, são: Cotripal, Puro Trato, Coopermil, Contribá, Cotrijal e Nutrepampa. Essas indústrias, por estarem mais próximas dos produtores de leite da região, estão com uma linha de produtos que, de certa forma, vêm contribuindo para a melhora da produção e manutenção dos animais presentes nas propriedades. No entanto, as cooperativas que ofertam insumos para os produtores exigem que eles sejam associados para obter descontos nos insumos adquiridos. Essa ligação permite que a cooperativa beneficie o produtor com preços menores e mais atraentes e, em contrapartida, os produtores consomem os produtos ofertados.

As empresas, além de ofertar a ração, também disponibilizam outros insumos para a produção. Esses insumos são considerados como "instrumentos de troca" para os produtores que utilizam como, por exemplo, medicamentos veterinários, adubos, fertilizantes, defensivos químicos, sal mineral, sementes, material genético, equipamentos de ordenha e refrigeração, máquinas agrícolas, embalagens, refrigeração e insumos em geral.

O estado do RS e a Região Noroeste, por meio destas empresas, vêm mostrando sua modernização do setor leiteiro. Esse movimento destaca-se pelo crescimento da atividade leiteira, diversidade de insumos produzidos pelas indústrias, produtividade média dos rebanhos e pela coleta do leite a granel nas propriedades produtoras. Esses eventos permitem que, em determinada área geográfica, ocorra a concentração de produtores, ocasionando a redução de custos de transportes, gerando ganhos de escala para as empresas, permitindo investimentos de grandes proporções na ampliação da capacidade produtiva da região, conforme descrito nos itens a seguir.

\section{Estrutura de processamento e distribuição dos produtores de leite no RS}

A atividade leiteira, tradicional no estado, tem potencial para ocupar espaços de mercado e proporcionar um efeito multiplicador interessante para o desenvolvimento de diferentes setores da economia regional (TRENNEPOHL, 2010). Esse efeito é perceptível na Região Noroeste, quando as indústrias processadoras de leite, ração e outras empresas de segmentos ligados à pecuária leiteira suscitam investimento para as cidades, com tecnologia e renda.

Cada atividade econômica integrante na pecuária leiteira gera demandas para operações complementares e subsidiárias. Porém, interessa observar as novas possibilidades de desenvolvimento, que, com a velocidade das informações, propagam-se e propiciam o aumento da capacidade inovativa das empresas de uma região. Essas atividades incentivam a especialização de certas etapas do processo produtivo, garantindo o surgimento de novas atividades econômicas, 
capazes de contribuir decisivamente na geração de mais emprego e renda (LIMA; LUCCA; TRENNEPOHL, 2014).

O modo de se produzir leite e o aumento da produtividade dos fatores de produção deram novos status à atividade de produção e comercialização de leite. Esse novo estilo vem evoluindo há mais de quatro décadas, e está buscando a profissionalização de todos os atores ligados à cadeia produtiva. O empreendedorismo e o bom gerenciamento das propriedades ajudam a entender o desempenho da pecuária de leite no RS (MARTINS et al., 2018).

As mudanças tecnológicas incorporadas ao longo das últimas décadas estão refletindo em maior eficiência do uso de todos os fatores de produção disponíveis no ambiente (MARTINS et al., 2018). Esta ação torna cada vez mais intensiva a produção nas propriedades e empresas fabricantes de insumos e matéria-prima.

Em uma perspectiva socioeconômica, as atividades ligadas à pecuária leiteira contribuem positivamente para a geração de emprego e renda no país. Segundo os dados da Relação Anual de Informações Sociais (RAIS) e Ministério do Trabalho e Emprego (MTE) (BRASIL, 2017), no RS, as três atividades da indústria de laticínios ligadas à empresa de transformação (preparação do leite; fabricação de laticínios e de sorvetes e outros gelados comestíveis) são responsável por 9.484 empregos diretos, o que representa 1,3\% do emprego industrial do estado, tomando-se por base as indústrias extrativas e de transformação, e 7,7\% do emprego de empresas de laticínios no Brasil (FAUTH; FEIX, 2015).

Com relação à estrutura de processamento de leite, foram identificadas 225 indústrias de diferentes portes em funcionamento no estado, conforme levantamento realizado pela Empresa Brasileira de Extensão Rural, Emater (2017). Essa estrutura de processamento pode ser observada na Tabela 1, que demonstra os tipos de inspeção presentes e atuantes no território gaúcho.

Tabela 1 - Estrutura de processamento de leite por tipo de inspeção

\begin{tabular}{lcc|cc}
\hline \multirow{2}{*}{ Tipo de Inspeção* } & \multirow{2}{*}{ Quantidade } & \multirow{2}{*}{ Percentual (\%) } & \multicolumn{2}{|c}{ Capacidade Instalada } \\
\cline { 4 - 5 } & & & Litros/dia & $\%$ \\
\hline Indústrias SIM & 153 & 68,0 & 324.643 & 1,7 \\
Indústrias CISPOA & 37 & 16,4 & 1.114 .190 & 6,0 \\
Indústrias SIF & 35 & 15,6 & 17.275 .000 & 92,3 \\
\hline Total RS & 225 & 100 & 18.713 .833 & 100,0 \\
\hline
\end{tabular}

* SIM - inspeção municipal, CISPOA - inspeção estadual, SIF - inspeção federal.

Fonte: Adaptado pelos autores com base na pesquisa realizada pela EMATER (2017). 
Os dados divulgados pela Emater (2017) sinalizam que a maioria das indústrias $(68,0 \%)$ é composta por pequenas unidades de processamento com inspeção municipal, que, no entanto, possuem uma capacidade instalada que representa apenas $1,7 \%$ do total no estado. Por outro lado, as 35 indústrias com inspeção federal possuem uma capacidade instalada para processamento de 17,2 milhões de litros/dia, o que equivale a $92,3 \%$ do total.

Essa diferença demostra o quanto as indústrias processadoras de leite estão evoluindo em relação às pequenas fábricas, cooperativas e queijarias. Esse movimento reprime a evolução das pequenas empresas, que apresentam dificuldades de seguir a legislação e muitas vezes são impedidas de participar de outros mercados.

A capacidade total de industrialização de leite no estado foi estimada em aproximadamente 18,7 milhões de litros/dia, ou 6,83 bilhões de litros/ano, considerando uma utilização de $100 \%$ da capacidade instalada nas unidades. A pesquisa realizada pela Emater (2017) demostra que as indústrias com inspeção municipal têm, em média, uma capacidade instalada de, aproximadamente, 324 litros/dia. Com inspeção federal, a capacidade instalada se aproxima dos 17,2 mil litros/dia e, no caso da inspeção estadual 1,1 milhão de litros/dia.

Dividindo a produção anual de leite destinada à indústria, conforme estimativa realizada pelo Instituto Brasileiro de Geografia e Estatística, IBGE (2018), ou seja, cerca de 4,5 bilhões de litros por 365 dias, obtém-se um valor médio de 12,32 milhões de litros de leite/dia. A partir dessa informação, estima-se que a produção de leite do RS destinada à indústria corresponda, na média do ano, a 71,63\% da capacidade instalada de industrialização, indicando uma ociosidade média de $28,37 \%$. Esse levantamento, demostra o potencial que está presente no parque industrial do estado e a sua ociosidade.

O setor primário onde ocorre o manejo e produção do leite insere um contingente expressivo de trabalhadores ao mercado de trabalho, cujas oportunidades de emprego estariam por vezes limitadas, exigindo uma maior qualificação. No setor da indústria de transformação, a ampliação das indústrias processadoras vem cada vez mais oportunizando trabalho em atividades ligadas à produção. $O$ setor de insumos, igualmente, vem ampliando o número de profissionais para disseminar seus produtos e serviços resultante dessa vigorosa expansão da produção agropecuária no país (ALVES; LÍCIO; CONTINI, 2016).

Esse conjunto de oportunidades e transformações impactou todos os ramos ligados à atividade láctea. Diante de tais possibilidades e desafios, é possível observar que a cadeia produtiva do leite está em transformação e que vem buscando aprimorar sua organização e crescimento socioeconômico. O amadurecimento da cadeia produtiva demonstra alterações nos cenários que se referem à produção, mas, ainda assim, são necessárias políticas públicas estruturantes para alavancar de vez a produção de leite. 
O que se percebe é que a produção de leite no RS vem crescendo continuamente. Dados estes mostram que as regiões que mais produzem leite estão se especializando e buscando maior eficiência. Nos últimos anos, segundos estudos realizados pela Emater (2017) e Marion Filho et al. (2015), houve aumento na produtividade e na produção de leite no estado, decorrente do melhoramento genético, da nutrição animal e de avanços tecnológicos. Alinhado a esses fatores também podem ser observados a visão de negócio, clima favorável, solo e o manejo adequado.

Diante desta conjuntura, o produtor de leite teve que realizar investimentos para aumentar a produtividade, sendo que muitos deles ocorreram para adequação às instruções normativas e exigências impostas pelo mercado. Estes investimentos vêm diferenciando os produtores quanto à escala de produção, níveis tecnológicos e produtores que alternam a produção de leite com outras atividades (MACHADO, 2001; SCHNEIDER, 2003).

Os produtores, ao longo dos anos, estão conseguindo transformar a atividade leiteira em uma fonte de renda mensal contribuindo fortemente para o equilíbrio do "caixa" da unidade de produção (OLIVEIRA et al., 2005). No estado, os produtores que vendem leite para indústrias, cooperativas e queijarias somam mais de 65 mil (EMATER, 2017). Dentre os produtores familiares, os que mais apresentam dificuldades, segundo Finamore et al. (2009), são os que produzem de forma menos tecnificada.

Para que estes produtores tenham êxitos nas atividades desenvolvidas na pecuária leiteira, é necessário abranger uma série de fatores, tanto de dentro como de fora da porteira, ou seja, dispor de informações geradas na propriedade e no mercado (LOPES, 2007). Também é preciso que as propriedades alcancem eficiência administrativa, planejamento e organização para que consigam estruturar suas unidades de produção e alcançar a rentabilidade.

O que vem ameaçando a permanência dos produtores na atividade é a intensa pressão da mercantilização organizada pelo mercado, caracterizada pela baixa produção alcançada, pagamento por volume, crédito e aquisição de maquinários. Esse processo, de acordo com a perspectiva de Polanyi (2000), é interpretado como um procedimento que resulta em uma dependência cada vez maior do produtor ao mercado.

Torna-se indispensável que os produtores de leite tenham o conhecimento aprofundado de seu negócio para não ficarem totalmente dependentes do mercado (SPAGNOL; PFÜLLER, 2010). Esse conhecimento é considerado um elemento básico para o desenvolvimento das atividades econômicas da propriedade, sendo que o produtor que não tiver a gestão de sua unidade (planejamento, controle dos custos, construção de metas e administração do processo como um todo), pode ser afetado por vários problemas (endividamento, 
perda da capacidade produtiva, venda do patrimônio para saldar suas dívidas e o abandono da atividade) (LIMA et al., 1995; SPAGNOL; PFÜLLER, 2010).

A partir do cenário de investimento e inovações no setor lácteo, o produtor que se modernizar e buscar rentabilidade para sua atividade possibilitará uma nova racionalidade no momento de fazer aplicações e desenvolver atividades na propriedade. Essa racionalidade adotada pode ser observada quando se analisa o volume de produção diária de leite, níveis de investimentos e a forma como são utilizados os instrumentos de trabalho. Deste modo, é possível analisar por meio do volume de produção diária divulgado pela Emater (2017), conforme a Tabela 2, como estão estruturadas e conectadas as propriedades do estado, conforme as escalas de produção diárias.

\section{Tabela 2 - Distribuição dos produtores de leite por volume diário de produção ( $\mathrm{n}^{\mathrm{o}}$ de produtores e \%)}

\begin{tabular}{lcc}
\hline Número de Produtores* que produzem leite & Total & Percentual $(\%)$ \\
\hline Até 200 litros por dia & 44.784 & 68,69 \\
Entre 201 a 500 litros por dia & 15.307 & 23,47 \\
Entre 501 a 1000 litros por dia & 3.923 & 6,02 \\
Mais de 1001 litros por dia & 1.188 & 1,82 \\
\hline Total & 65.202 & 100 \\
\hline
\end{tabular}

* Referente aos produtores que vendem leite para indústrias, cooperativas ou queijarias ou que processam a produção em agroindústria própria legalizada.

Fonte: Adaptado pelos autores com base nos dados da Emater (2017).

A distribuição dos produtores de leite total do RS conforme o destino predominante da produção, informado pela Emater (2017), aproxima-se dos 173.706 produtores. Dentre este número, 65.202 produtores vendem seu produto para alguma indústria, cooperativa ou queijaria; 11.339 encontram-se na informalidade, vendendo leite cru diretamente para os consumidores, ou comercializando derivados lácteos de fabricação caseira; os demais produzem para o consumo familiar ou oferecem outro destino à produção (EMATER, 2017).

Do ponto de vista social, as proposições de formas alternativas de organização do trabalho, motivadas por uma nova racionalidade, permitem que famílias que vivem na informalidade, e até mesmo os que comercializam seus produtos para alguma indústria, pudessem ressignificar seus processos e assim buscar alternativas para sua sobrevivência e permanência na atividade. Caso as alternativas adotadas sejam incompatíveis com os estilos de produtores, a vasão será em grande escala, demandando políticas públicas engajadas com a perspectiva de transformação social. Segundo Silva Neto; Preste de Lima; Basso (2003), os produtores de leite 
que aderirem a essa nova racionalidade deverão buscar eficiência, profissionalização e maiores escalas de produção com menores custos, para continuarem desenvolvendo suas atividades em suas unidades de produção.

Não havendo oportunidades e condições de investir na atividade, os produtores que, de modo geral, apresentarem baixo nível tecnológico, dificuldade de acesso a crédito, terras menos produtivas, indisponibilidade de mão de obra e animais não melhorados geneticamente, estarão sujeitos a se manter na atividade apenas garantindo uma remuneração mínima necessária para sua sobrevivência (PEDROSO, 2002).

Os indicadores de escala de produção, apresentados na Tabela 2, representam um cenário heterogêneo. Eles demonstram um panorama de como as propriedades produtoras de leite do RS estão se organizando e buscando essa interação com o mercado.

Segundo Delgado e Bergamosco (2017), os produtores, ao tentarem se inserir ao mercado, ajustam-se aos padrões de exigência mercantil, além dos apelos de competitividade e rentabilidade que essa nova escala pode requerer. Neste caso, percebe-se que os agricultores familiares com baixa tecnificação na propriedade, com limitações financeiras, dificuldade de acesso à informação, escassez de mão de obra especializada e assistência técnica estão em busca de integração ao mercado.

Em relação à área destinada à produção leiteira, os estabelecimentos agropecuários do RS vinculados a algum tipo de indústria processadora de leite possuem propriedades com área média estimada em 19,1 hectares para produzir a matéria prima (EMATER, 2017). Logo, os produtores do estado, mesmo possuindo uma pequena área para fazer o manejo dos animais, vêm se reestruturando para garantir uma produção adequada para sua permanência na atividade requerendo o aumento da produtividade.

Na Tabela 3 é possível observar a evolução da produção leiteira nas últimas décadas. Comparando os dados do IBGE de 1960 com a estimativa do ano de 2017, percebeu-se um crescimento de 752,29\% para a produção total de leite no estado. Em relação à produtividade média leiteira, houve um crescimento de $364,76 \%$. Sendo assim, nota-se que o RS acompanhou o país no tocante ao crescimento da produção e produtividade leiteira nas últimas décadas, do Século XX e início do XXI. 
Tabela 3 - Produção de leite no Rio Grande do Sul de 1960 a 2017

\begin{tabular}{lccc}
\hline Ano & Vacas ordenhadas & Produção mil litros & $\begin{array}{c}\text { Produtividade média } \\
\text { (litros/vacas/ano) }\end{array}$ \\
\hline 1960 & 668.905 & 605.034 & 905 \\
1970 & 815.206 & 778.479 & 955 \\
1975 & 836.504 & 815.718 & 975 \\
1980 & 992.109 & 1.236 .385 & 1246 \\
1985 & 1.070 .173 & 1.129 .134 & 1055 \\
1990 & 1.173 .862 & 1.451 .797 & 1237 \\
1995 & 1.251 .487 & 1.710 .677 & 1367 \\
2000 & 1.164 .912 & 2.102 .018 & 1804 \\
2005 & 1.203 .601 & 2.467 .630 & 2050 \\
2010 & 1.495 .518 & 3.633 .834 & 2430 \\
2014 & 1.544 .072 & 4.684 .960 & 3034 \\
2015 & 1.496 .671 & 4.599 .925 & 3073 \\
2016 & 1.461 .315 & 4.613 .780 & 3157 \\
$2017 *$ & 1.368 .586 & 4.551 .601 & 3301 \\
\hline
\end{tabular}

* Os dados do último ano divulgado são resultados preliminares e podem sofrer alterações.

Fonte: Adaptado pelos autores com base em dados do IBGE (2018) e Pesquisa da Pecuária Municipal (2018).

Nos últimos anos a produção de leite no RS tem apresentado algumas variações negativas em relação aos anteriores (2014/2015 e 2016/2017). Porém, está crescendo sistematicamente, mesmo nos ambientes de intervenções do governo via planos econômicos, com preços controlados, importações, desregulamentação da economia, instruções normativas, fusões entre empresas e saída de produtores da atividade (VILELA et al., 2017). Esses episódios revolucionaram o setor lácteo trazendo distorções que prejudicaram a atividade leiteira em alguns momentos (desnacionalização das empresas brasileiras, invasão de produtos importados) e em outros forçaram a modernização (ordenhas mecanizadas, genética etc.) da atividade.

A nova dinâmica do setor tem motivado todos os agentes integrantes do âmbito da atividade leiteira na propagação de novas técnicas, manejos e cuidados na gestão das propriedades. $\mathrm{O}$ amadurecimento da cadeia produtiva gera entre os produtores uma maior aproximação e discussão dos desafios e oportunidades que estão presenciando e qual será a tendência que poderá trazer reflexos positivos no futuro (VILELA; RESENDE, 2014).

A expansão da produção de leite da forma com vem evoluindo, continuará neste ritmo e com melhorias nas próximas décadas (CARVALHO et al., 2007). A 
tendência é de que a produção ultrapasse consideravelmente a expansão do consumo, destinando o excedente para a exportação. Para que isso aconteça é imprescindível que setores estratégicos da atividade em conjunto com os produtores de leite se reorganizem e ajustem seus custos e processos para atender as demandas necessárias à exportação.

Para procurar entender o crescimento da produção de leite no período analisado, é importante compreender o perfil produtivo da atividade leiteira que se encontra no estado (PEDROSO 2002; EMATER, 2017). Algumas variáveis (tecnologia, investimento, genética e gestão) são relevantes para compreender o aspecto bemsucedido e o motivo da alta da produtividade apresentada nos últimos anos e da diminuição das vacas ordenhadas. Certamente, o manejo com instrumentos (Free Stall, Compost Barn, sistema de pastejo rotacionado, ordenha mecanizada, eficiência reprodutiva, melhoria na nutrição, melhoramento de pastagens, inseminação artificial, maiores cuidados higiênicos e sanitários, melhoria da genética do rebanho e melhor aproveitamento dos recursos disponíveis para esta produção) tem contribuído para o ganho em escala e para o melhor aproveitamento da área disponível na propriedade.

A obtenção de maiores níveis de produtividade média dos animais em propriedades produtoras de leite é condição necessária para um desempenho econômico eficiente (LOPES; REIS; YAMAGUCHI, 2007). Para obter escalas de produção cada vez maiores, é crucial que ocorra a profissionalização e especialização dos produtores, bem como a redução na variação sazonal da produção leiteira (CASTRO et al., 1998). Além disso, as regiões produtoras de leite localizadas mais ao norte do estado apresentam uma série de atrativos, tais como clima temperado, disponibilidade de água, estrutura fundiária dominada por pequenas propriedades, mão de obra familiar e acesso dos produtores a crédito subsidiado (PAIVA; ROCHA; THOMAS, 2014; FEIX; JÚNIOR; AGRANONIK, 2017).

A redução do número de vacas ordenhadas é um indicador importantíssimo que vem sendo divulgado nas últimas décadas, em especial na mesorregião Noroeste Rio-Grandense por ser considerada uma região dinâmica e com maiores índices de produtividade do estado. Esse indicador demonstra que os rebanhos estão sendo mais bem aproveitados, visando sua alta eficiência produtiva e técnicas reprodutivas mais avançadas para a obtenção de gestações e melhoramento genético (PRADIEÉ; PEGORARO; DERETI, 2017).

Segundo Milani et al., (2012), os produtores do estado investem cada vez mais em alimentação, genética apurada e infraestrutura que auxiliam em uma maior produtividade. Esses investimentos fazem com que os animais que não produzam conforme a necessidade da propriedade, sejam descartados. Esse descarte tem ocorrido com uma abrangência maior nos últimos anos, fazendo com o os 
rebanhos venham diminuído e, como consequência, tem-se o aumento da produção.

A maioria dos produtores que ainda permanecem na atividade estão buscando inovar e melhorar os processos ligados à unidade de produção. O desenvolvimento tecnológico e o conhecimento adquirido estão demostrando mudanças nos estilos de produtores que permanecem integrados na pecuária leiteira. Neste sentido, o grande desafio da atividade continua sendo a maior profissionalização das famílias e a ampliação da escala de produção das unidades agrícolas, com vistas ao acréscimo do rendimento por animal, por área utilizada e por estabelecimento, com reflexos na redução dos custos e na produtividade do trabalho.

\section{Considerações finais}

A partir das discussões realizadas evidencia-se que a pecuária leiteira se tornou uma atividade disseminada na Região Noroeste do estado do RS, destacando-se apesar da forte tradição agrícola voltada à atividade de produção de grãos. Não se trata de iniciar uma atividade nova, sobre a qual pouco se conhece e muito precisa ser buscado. Ao contrário, é uma atividade tradicional da região cujo potencial de expansão, que era contido por diversas razões, se explica com muita clareza.

A nova dinâmica do setor tem motivado todos os agentes integrantes do âmbito da atividade leiteira, na propagação de novas técnicas, manejos e cuidados na gestão das propriedades. $\mathrm{O}$ amadurecimento da cadeia produtiva gera entre os produtores uma maior aproximação e discussão dos desafios e oportunidades que estão presenciando e qual será a tendência que poderá trazer reflexos positivos no futuro.

Sobre a expansão da produção de leite acredita-se que poderá continuar neste ritmo e com melhorias nas próximas décadas. Para se obter escalas de produção cada vez maiores, é crucial que ocorra a profissionalização e especialização dos produtores, bem como a redução na variação sazonal da produção leiteira e gestão nas unidades de produção.

Porém, é de extrema relevância observar as novas possibilidades de desenvolvimento que se propagam com a velocidade das informações e propiciam o aumento da capacidade inovativa das empresas da região. A geração de emprego e renda surge com a presença das novas atividades econômicas, proporcionando qualificação profissional de produtores e técnicos que estão envolvidos diretamente na atividade e das indústrias com novos produtos.

O grande número de empresas com plantas industriais na Região Noroeste do estado, indica claramente a possibilidade de ocupar os espaços de mercado que se 
abrem para a produção de leite. Os investimentos realizados sinalizam que existem movimentos neste sentido. Os efeitos multiplicativos que a atividade apresenta podem ser de fundamental importância para movimentar outros setores da economia regional e expandir a cadeia produtiva do leite.

A produção de leite, na região objeto de estudo, necessita de uma maior mecanização e especialização para que possa atender a escala mundial com a qualidade preconizada. Conhecendo esta necessidade e a inclusão do noroeste do RS entre as principais regiões produtoras de leite do Brasil, é possível inferir que um próspero mercado está em desenvolvimento, tendo como influentes participantes os produtores da região, que de sua ótica buscam ampliação da renda e melhores condições de trabalho.

A contribuição deste estudo se dá no sentido de evidenciar as mudanças que vêm ocorrendo na cadeia produtiva do leite, bem como as razões e as consequências dessas transformações, especificamente a diversificação de atividades pelos produtores que as praticam e implantam, como estratégia de permanência na atividade. Neste contexto, retorna-se à questão de pesquisa reforçando que as variáveis discutidas são consideradas instrumentos necessários para que a atividade continue se desenvolvendo e gerando trabalho para todos os agentes da cadeia produtiva.

\section{Referências}

ALVES, E. R. de A.; LÍCIO, A. M. A.; CONTINI, E. Perspectivas do Brasil no comércio internacional de lácteos. In: Pecuária de leite no Brasil: cenários e avanços tecnológicos / Duarte Vilela [et al.] editores técnicos. Brasília/DF: Embrapa, 2016. Disponível em: $<$ https://ainfo.cnptia.embrapa.br/digital/bitstream/item/164236/1/Pecuaria-deleite-no-Brasil.pdf>. Acesso em: 24 out. 2018.

\section{BASSO, D.; SILVA NETO, B. Controvérsias sobre profissionalização e} desenvolvimento na agricultura: o caso da produção de leite no Rio Grande do Sul. 1999 Disponível em:

<https:// revistas.fee.tche.br/index.php/indicadores/article/view/1742/2110>. Acesso em: 12 dez. 2015.

BATALHA, Mario Otavio (Coord.). Gestão agroindustrial. Vol. 1.3 ed. São Paulo: Atlas, 2007. 
BRASIL. Ministério da Agricultura, Pecuária e Abastecimento (MAPA). Valor Bruto da Produção da Agropecuária. Brasília/DF, 2017. Disponível em: <http://www.agricultura.gov.br/assuntos/politica-agricola/valor-bruto-daproducao-agropecuaria-vbp $>$. Acesso em: 18 jul. 2018.

BREITENBACH, R.; DE SOUZA, R. S. Estrutura industrial na cadeia produtiva do leite e a interferência no desenvolvimento regional. REAd, Porto Alegre, Edição 82, N. 3, setembro/dezembro 2015, p. 750-781. Disponível em: <https://www.researchgate.net/publication/300365924_estrutura_conduta_e_go vernanca_na_cadeia_produtiva_do_leite_um_estudo_multicaso_no_rio_grande_d o_sul>. Acesso em: 23 abr. 2018.

BRUM, Argemiro Jacó. Modernização da agricultura: trigo e soja. Petrópolis: Vozes, 1988.

BRUM, Argemiro Luís. Mercado e cadeias produtivas. In: SIEDENBERG, Dieter (Org.) Desenvolvimento sob múltiplos olhares. Ijuí: Ed. Unijuí, 2012. p. 187206.

CANZIANI, José Roberto Fernandes. Cadeias agroindustriais: o programa empreendedor rural. Curitiba: SENAR-PR, 2003.

CANZIANI, José Roberto Fernandes. Planejamento de propriedades rurais. Anais Seminário Sul-Brasileiro de Administração Rural. Passo Fundo: UPF, 2002.

CARVALHO, G. R.; FORTES DE OLIVEIRA, A. O setor lácteo em perspectiva. Campinas: EMBRAPA, 22 p. (Circular técnica, n. 11), 2006. Disponível em: <https://ainfo.cnptia.embrapa.br/digital/bitstream/item/117887/1/4364.pdf>. Acesso em: 16.ago. 2015.

CARVALHO, Marcelo Pereira de et al. Cenários para o leite no Brasil em 2020. Juiz de Fora: Embrapa Gado de Leite, 2007. 190 p. Disponível em: <http://www.bibliotecas.sebrae.com.br/chronus/ARQUIVOS_CHRONUS/bds /bds.nsf/0E9DE01C39E70F6D832575B0005FE0B4/\$File/NT00040DEE.pdf>. Acesso em: 03 mai. 2018. 
CARVALHO, Vera Regina. Mudanças patrimoniais na indústria de laticínios no Brasil: reações às mudanças institucionais e concorrenciais dos anos 80 e 90. 2000. Disponível em: <http://cdn.fee.tche.br/jornadas/1/s3a8.pdf>. Acesso em: 15 ago. 2017.

CASTRO, Cleber Carvalho et al. Estudo da cadeia láctea do Rio Grande do Sul: uma abordagem das relações entre os elos da produção, industrialização e distribuição. Revista Administração Contemporânea. Vol. 2, n. 1, p. 143-164, 1998. Disponível em:

$<$ http:/ / www.scielo.br/scielo.php?script=sci_arttext\&pid=S1415-

65551998000100009>. Acesso em: 22 nov. 2017.

CONTERATO, Marcelo Antonio. Dinâmicas regionais do desenvolvimento rural e estilos de agricultura familiar: uma análise a partir do Rio Grande do Sul. 2008. 290p. Tese (Doutorado em Desenvolvimento Rural), Programa de Pósgraduação em Desenvolvimento Rural, Universidade Federal do Rio Grande do Sul, Porto Alegre. Disponível em: <https://www.lume.ufrgs.br/bitstream/handle/10183/15624/000661531.pdf?se quence $=1>$. Acesso em: 12 maio. 2015.

DELGADO, G. C.; BERGAMASCO, S. M. P. P. (org.) Agricultura familiar brasileira: desafios e perspectivas de futuro. Brasília: Ministério do Desenvolvimento Agrário, 2017. Disponível em:

<http://www.mda.gov.br/sitemda/sites/sitemda/files/user_img_1756/Agricultu ra\%20Familiar_WEB_LEVE.pdf>. Acesso em: 23 out 2018.

DUARTE, Virgínia. Ideas for milk: gerando ideias e estimulando negócios na cadeia do leite. 2017. Ideas for Milk. Disponível em:

$<$ http://ticemfoco.com.br/ideas-for-milk-gerando-ideias-e-estimulando-negociosna-cadeia-do-leite/>. Acesso em: 30 out. 2018.

\section{EMATER. Relatório socioeconômico da cadeia produtiva do leite no Rio}

Grande do Sul (elaboração: Jaime Eduardo Ries). Porto Alegre: Emater/RS: Ascar, 2017. 64p. Disponível em:

<http://biblioteca.emater.tche.br:8080/pergamumweb/vinculos/000006/000006 79.pdf>. Acesso em: 20 fev. 2018. 
EMBRAPA GADO DE LEITE. Indicadores: Leite e Derivados, Ano 9, N. 78. Juiz de Fora: Embrapa Gado de Leite, 2018. Disponível em: <https://ainfo.cnptia.embrapa.br/digital/bitstream/item/176816/1/Indicadoresleite-78-Maio.pdf>. Acesso em: 31 Dez. 2018.

\section{FAUTH, E. M.; FEIX, R. D. Aglomeração produtiva de laticínios nos}

Coredes Fronteira Noroeste e Celeiro. Porto Alegre: FEE, 2015. Relatório do Projeto Estudo de Aglomerações Industriais e Agroindustriais no RS. Disponível em: <https://www.fee.rs.gov.br/wp-content/uploads/2016/06/201606068laticinios-fronteira-noroeste-e-celeiro-relatorio1.pdf $>$. Acesso em: 25 jun. 2018.

\section{FEE. Fundação de Economia e Estatística do Estado do Rio Grande do}

Sul. 2017. Disponível em: <http://www.fee.rs.gov.br>. Acesso em: 08 dez. 2017.

FEIX, R. D.; LEUSIN JÚNIOR, S.; AGRANONIK; C. Painel do agronegócio no Rio Grande do Sul 2017. Porto Alegre: FEE, 2017. Disponível em: <https://www.agricultura.rs.gov.br/upload/arquivos/201709/04134710-paineldo-agronegocio-do-rio-grande-do-sul-2017.pdf>. Acesso em: 22 de mai. 2018.

FINAMORE, Eduardo Belinaso Monteiro de Castro et al. Características dos produtores de leite do RS: uma análise a partir do Corede Nordeste. In: XLIII Congresso da Sociedade Brasileira de Administração, Economia e Sociologia Rural. 2009. Porto Alegre. Anais. Ribeirão Preto: Sociedade Brasileira de Administração, Economia e Sociologia Rural, 2009. Disponível em: <http://www.sober.org.br/palestra/13/1299.pdf>. Acesso em: 23 jun 2017.

FONTOURA Luiz Fernando Mazzini. A modernização da agricultura e a urbanização incompleta: a situação de algumas cidades da campanha gaúcha. CaderNAU-Cadernos do Núcleo de Análises Urbanas, v.7, n. 1, 2014, p. 27-47. Disponível em: <https://periodicos.furg.br/cnau/article/view/4830/3128>. Acesso em: 31 out. 2018.

GIGANTE, Mirna Lúcia. Importância da qualidade do leite no processamento de produtos lácteos. In: DÜRR, J. W.; CARVALHO, M. P. de; SANTOS, M. V. (org.) $\mathbf{O}$ compromisso com a qualidade do leite no Brasil. Passo Fundo: UPF, 2004. p. 235-254. 
Gil, Antonio Carlos. Métodos e técnicas de pesquisa social. 6. ed. São Paulo: Atlas, 2008.

GOMES, Sebastião Teixeira. Evolução recente e perspectivas da produção de leite no Brasil. In: GOMES, A. T.; LEITE, J. L. B.; CARNEIRO, A. V. (org.) O agronegócio do leite no Brasil. Juiz de Fora: Embrapa Gado de Leite, 2001. p. 49-61. Disponível em: <http://www.sober.org.br/palestra/12/04O234.pdf>. Acesso em: 14 maio. 2018.

HANSEN, Peter Bent. Um modelo meso-análitico de medição de desempenho competitivo de cadeias produtivas. Tese (Doutorado em Engenharia de Produção) UFRGS, Porto Alegre, 2004. Disponível em: <https://www.lume.ufrgs.br/bitstream/handle/10183/9020/000459101.pdf?seq uence>. Acesso em: 30 out. 2018.

IBGE. Instituto Brasileiro de Geografia e Estatística. Pesquisa trimestral do leite. 2018. Disponível em: < https:/ / sidra.ibge.gov.br/tabela/1086>. Acesso em: 22 jan. 2018.

IBGE. Instituto Brasileiro de Geografia e Estatística. Produção da Pecuária Municipal 2017. 2017. Disponível em:

<https://biblioteca.ibge.gov.br/visualizacao/periodicos/84/ppm_2017_v45_br_i nformativo.pdf>. Acesso em: 23 abr. 2018.

KAGEYAMA, Ângela. Desenvolvimento rural: conceito e Medida. Cadernos de Ciência \& Tecnologia, Brasília, v. 21, n. 3, p. 379-408, set.-dez. 2004. Disponível em: <https://seer.sct.embrapa.br/index.php/cct/article/view/8702/4887>. Acesso em: 10 jun. 2015.

JANK, Marcos Sawaya et al. O agribusiness do leite no Brasil. São Paulo: Pensa; Milkbizz. 1999.

JANK, M. S.; GALAN, V. B. Competitividade do sistema agroindustrial do leite. São Paulo: USP-PENSA, 1999.

JANTSCH, E. M. et al. Caracterização da atividade leiteira em sistemas de produção de base familiar na região noroeste do Rio Grande do Sul. Anais do 
Salão do Conhecimento e XII Jornada de Extensão UNIJUİ. Ijuí/RS. 2011. Disponível em:<https://ainfo.cnptia.embrapa.br/digital/bitstream/item/50336/1/Artigonos-anais.pdf $>$. Acesso em: 03 out. 2016.

LIMA, Arlindo Prestes de et al. administração da unidade de produção familiar: modalidades de trabalho com agricultores. Ijuí: Unijuí, 1995.

LIMA, G. G.; LUCCA, E. J.; TRENNEPOHL, D. Expansão da cadeia produtiva do leite e seu potencial de impacto no desenvolvimento da Região Noroeste Rio-Grandense. 2014. Disponível em <https://www.fee.rs.gov.br/wp-content/uploads/2014/05/201405267eegmesa14-expansaocadeiaprodutivaleitenoroesters.pdf> Acesso em: 23 nov. 2015.

LOPES, André Dias. Caracterização de unidades produtoras de leite na área de abrangência do escritório de Desenvolvimento Rural de Jaboticabal SP. 2007. 97p. Dissertação (Mestrado em Zootecnia). Universidade Estadual Paulista "Júlio de Mesquita Filho". São Paulo, 2007. Disponível em: <http://www.fcav.unesp.br/download/pgtrabs/zoo/m/3033.pdf>. Acesso em: 10 nov. 2017.

LOPES, P. F.; REIS, R. P.; YAMAGUCHI, L. C. T. Custos e escala de produção na pecuária leiteira: estudo nos principais estados produtores do Brasil. RER, Rio de Janeiro, vol. 45, N. 3, p. 567-590, jul.-set. 2007. Disponível em: <http://www.scielo.br/pdf/resr/v45n3/a02v45n3.pdf>. Acesso em: 22 de mai. 2018.

MACHADO, Roberto Tormes. Análise socioeconômica e perspectivas de desenvolvimento para os produtores de leite do município de Crissiumal RS. 2001. 155p. Dissertação (Mestrado em Desenvolvimento Rural). Universidade Federal do Rio Grande do Sul, Porto Alegre, 2001. Disponível em:

<https://lume.ufrgs.br/bitstream/handle/10183/2201/000315862.pdf?sequence =1\&isAllowed $=\mathrm{y}>$. Acesso em: 10 set. 2015 .

MARTINS, Paulo do Carmo et al. Anuário do leite 2018. Coord. Geral. Embrapa.br/gado-de-leite. 2018. Disponível em:

<https://www.embrapa.br/busca-de-noticias/-/ noticia/36560390/anuario-doleite-2018-e-lancado-na-agroleite>. Acesso em: 21 dez. 2018. 
MARION FILHO, Pascoal. José et al. Concentração regional e especialização na produção de leite do Rio Grande do Sul (1990 - 2010). Revista Brasileira de Gestão e Desenvolvimento Regional v. 11, n. 1, p. 224-242, jan.-abr. 2015. Disponível em:

<http://www.rbgdr.net/revista/index.php/rbgdr/article/view/1616/435>. Acesso em: 25 out. 2016.

MILANI, Renata et al. Diversificação e perspectivas de investimentos entre produtores de leite. In: ENCONTRO DE ECONOMIA GAÚCHA, 6, 2012, Porto Alegre. Anais. Porto Alegre: PUCRS, 2012. Disponível em:

<http://cdn.fee.tche.br/eeg/6/mesa15/Diversificacao_e_Perspectivas_de_Invest imentos_entre_Produtores_de_Leite.pdf>.Acesso em: 10 ago. 2018.

MONARDES, Humberto Gonzallo. Reflexões sobre a qualidade do leite. In: DÜRR, J. W.; CARVALHO, M. P. de; SANTOS, M. V. (org.) O compromisso com a qualidade do leite no Brasil. Passo Fundo: UPF, 2004. p. 11-37.

MONTOYA, M. A.; FINAMORE, E. B. M. de C. Características dos produtores de leite do RS: uma análise a partir do Corede Nordeste. Indicadores Econômicos FEE, Porto Alegre, v. 37, n. 4, p. 213-224, 2010. Disponível em: <https:// revistas.fee.tche.br/index.php/indicadores/article/view/2348/2784>. Acesso em:22 jun. 2017.

MONTOYA, M. A.; FINAMORE, E. B. M. de C. Delimitação e encadeamento de sistemas agroindustriais: o caso do complexo lácteo do Rio Grande do Sul. Economia Aplicada, Ribeirão Preto, n. 9 (4), p. 663- 682, out-dez, 2005. Disponível em: <http://www.scielo.br/pdf/ecoa/v9n4/v9n4a08>. Acesso em:22 jun. 2017.

NAVARRO, Zander. Desenvolvimento rural no Brasil: os limites do passado e os caminhos do futuro. Estudos Avançados, v. 15, N. 43, p. 83-100, 2001.

Disponível em: <http:/ /www.scielo.br/scielo.php?script=sci_arttext\&pid=S010340142001000300009>. Acesso em: 15. jun. 2015.

OLIVEIRA, Sheila Mirian de et al. Pequeno produtor na cadeia produtiva do leite: experiências de cooperação, incorporação de tecnologia e aquisição de competitividade. In: XLIII Congresso da Sociedade Brasileira de 
Administração, Economia e Sociologia Rural. 2005. Ribeirão Preto. Anais... Ribeirão Preto: Sociedade Brasileira de Administração, Economia e Sociologia Rural, 2005. Disponível em: < http://www.sober.org.br/palestra/2/666.pdf>. Acesso em out 2018.

PAIVA, C. A. N.; ROCHA, A. L.; THOMAS, G. A competitividade estrutural da agroindústria do leite no Rio Grande do Sul. In: BASSO, D.; TRENNEPOHL, D. (org.) Planejamento estratégico de arranjos produtivos locais: plano de desenvolvimento do APL agropecuário familiar da Região Celeiro 2014-2020. Ijuí: UNIJUI, 2014, vol. 1, p. 41-74.

PEDROSO, Glaucilene Dias. Setor leiteiro: as percepções dos produtores do RS sobre as transformações delineadas na década de 90. Dissertação de mestrado UFRGS 2002. Disponível em:

<https://lume.ufrgs.br/bitstream/handle/10183/2323/000317807.pdf?sequence $=1$ \&is Allowed $=\mathrm{y}>$. Acesso em: 22 out. 2018 .

POLANYI, Karl. A grande transformação. 2 ed. Rio de Janeiro: Elsevier, Compus, 2000. Disponível em:

<https://edisciplinas.usp.br/pluginfile.php/1973131/mod_resource/content/1/ Polanyi_A\%20grande \%20transform. \%20-\%20livro\%20todo.pdf $>$. Acesso em: 30 abr. 2015.

PORTO, Rafael Gastal et al. Pecuária familiar: a emergência de uma categoria social no Sul do Brasil. Revista de Economia e Sociologia Rural, Piracicaba, vol. 48, N. 2, p. 473-494, abr/jun 2010. Disponível em:

<http://www.scielo.br/pdf/resr/v48n2/10.pdf>. Acesso em: 22 abr. 2018.

PLOEG, Jan Douwe Van Der. Camponeses e impérios alimentares. Lutas por autonomia e sustentabilidade na era da globalização. Porto Alegre: Editora da UFRGS. 372p. 2008.

PLOEG, Jan Douwe Van Der et al. Rural development: from practices and policies towards theory. Sociologia Ruralis, Assen, v. 40, N. 4, p. 391-408, 2000.

PRADIEÉ, J.; PEGORARO, L. M. C..; DERETI, R. M. Evolução da pesquisa em pecuária leiteira. Brasília/DF: Embrapa, 2017. 76p. Disponível em: 
$<$ https://ainfo.cnptia.embrapa.br/digital/bitstream/item/169206/1/Evolucaoda-Pesquisa-em-Pecuaria-Leiteira.pdf $>$. Acesso em: 23 nov. 2018.

PROCHNIK, Victor; HAGUENAUER, Lia. Cadeias produtivas e oportunidades de investimento no Nordeste Brasileiro. Revista Análise Econômica. Ano 20, N. 38, set. 2002. Disponível em:

$<$ http://www.ie.ufrj.br/images/cadeias_produtivas/cadeias_produtivas_e_oportu nidades_de_investimento_no_nordeste_brasileiro.pdf>. Acesso em 30 out. 2018.

SILVA NETO, Benedito.; BASSO, David. A produção de leite como estratégia de desenvolvimento para o Rio Grande do Sul. Revista Desenvolvimento em Questão, ano 3, N. 5 jan.-jun. 2005. p. 53-72. Disponível em: $<$ https://www.redalyc.org/pdf/752/75230504.pdf>. Acesso em: 23 jan. 2016.

SILVA NETO, B.; PRESTES DE LIMA, A. de J.; BASSO, D. Incerteza, racionalidade e procedimentos em ações de Desenvolvimento local. Revista Desenvolvimento em Questão, Ano 1, N. 2, jul.-dez. 2003, p 123-149.

Disponível em:

<http://beneweb.com.br/resources/Incerteza, $\% 20$ racionalidade $\% 20 \mathrm{e} \% 20$ proced imentos $\% 20 \mathrm{em} \% 20 \mathrm{a} \% \mathrm{C} 3 \% \mathrm{~A} 7 \% \mathrm{C} 3 \% \mathrm{~B} 5 \mathrm{es} \% 20 \mathrm{de} \% 20$ desenvolvimento $\% 20$ rural. pdf>. Acesso em: 10 set. 2017.

SCHNEIDER, Sérgio. A pluriatividade na agricultura familiar. Porto Alegre: Editora da UFRGS, 2003.

SPAGNOL, R.; PFÜLLER, E. E. A administração rural como processo de gestão das propriedades rurais. Revista de Administração e Ciências Contábeis do IDEAU, vol. 5, N.10, jan.-jun. 2010. Disponível em:

<https://www.ideau.com.br/getulio/restrito/upload/revistasartigos/90_1.pdf>. Acesso em: 07 out. 2018.

TEIXEIRA, Jodenir Calixto. Modernização da agricultura no Brasil: impactos econômicos, sociais e ambientais. Revista Eletrônica da Associação dos Geógrafos Brasileiros, vol. 2, N. 2, set. 2005. Disponível em: <http://seer.ufms.br/index.php/RevAGB/article/viewFile/1339/854>. Acesso em: 07 out. 2018. 
TOMICH; Thierry Ribeiro et al. Nutrição de precisão na pecuária leiteira.

Cadernos Técnicos de Veterinária e Zootecnia, No 79, dez. 2015. Disponível em: < https://ainfo.cnptia.embrapa.br/digital/bitstream/item/139557/1/Cnpgl2015-CadTecVetZoot-Nutricao.pdf>. Acesso em: 23 out. 2018.

TRENNEPOHL, Dilson. Avaliação de potencialidades econômicas para o desenvolvimento regional. Ijuí: Ed. Unijuí, 2011.

TRENNEPOHL, Dilson. Avaliação da contribuição potencial das principais atividades agropecuárias para o desenvolvimento econômico da Região Noroeste do Rio Grande do Sul. Tese (Doutorado em Desenvolvimento Regional) - Universidade de Santa Cruz do Sul - UNISC. 2010. Disponível em: <http://www.centrocelsofurtado.org.br/arquivos/image/201204271615190.Tese \%20-\%20Dilson\%20Completa.pdf>. Acesso em: 12 set. 2015.

VIANA, Giomar. FERRAS, Robson Paulo Ribeiro. A cadeia produtiva do leite: um estudo sobre a organização da cadeia e sua importância para o desenvolvimento regional. Revista Capital Científico do Setor de Ciências Sociais Aplicadas, vol. 5, N. 1, jan.-dez. 2007. Disponível em: $<$ https://revistas.unicentro.br/index.php/capitalcientifico/article/view/718/841 >. Acesso em: 23 abr. 2018.

VIEIRA FILHO, José Eustáquio Ribeiro; FISHLOW, Albert. Agricultura e indústria no Brasil: inovação e competitividade. Brasília: Ipea, 2017. Disponível em:

<http://ipea.gov.br/agencia/images/stories/PDFs/livros/livros/170404_livro_a gricultura_no_brasil.pdf $>$. Acesso em: 10 abr. 2018.

VILELA, Duarte et al. A evolução do leite no Brasil em cinco décadas. Revista de Política e Economia, Ano XXVI, N. 1, jan.-mar. 2017. Disponível em: <https://ainfo.cnptia.embrapa.br/digital/bitstream/item/163208/1/Evolucaodo-leite-no-brasil.pdf>. Acesso em: 24 out. 2017.

VILELA, D.; RESENDE, J. C. de. Cenário para a produção de leite no Brasil na próxima década. In: Simpósio sobre sustentabilidade da pecuária leiteria na Região Sul do Brasil; Seminário dos centros mesorregionais de excelência em tecnologia do leite, 2014, Maringá. Anais. UEM, 2014. Disponível em: 
<https://ainfo.cnptia.embrapa.br/digital/bitstream/item/130329/1/ArtigoAnais-6-Sul-Leite-Vilela.pdf>. Acesso em: 23 set. 2017.

ZYLBERSZTAJN, Decio. Conceitos gerais, evolução e apresentação do sistema agroindustrial. In: ZYLBERSZTAJN, D.; NEVES, M. F. (org.) Economia e gestão dos negócios agroalimentares: indústria de alimentos, indústria de insumos, produção agropecuária, distribuição. São Paulo: Pioneira; 2000, 428p.

Endereço para correspondência:

Emerson Juliano Lucca - lucca.emerson@gmail.com Avenida Independência, 2293 - Universitário 96815-900 Santa Cruz do Sul/RS, Brasil

Silvio Cezar Arend-silvio@unisc.br Avenida Independência, 2293 - Universitário 96815-900 Santa Cruz do Sul/RS, Brasil 
Emerson Juliano Lucca e Silvio Cezar Arend

142 | Revista Brasileira de Desenvolvimento Regional, Blumenau, 7 (3), P. 107-142, 2019 